\title{
Contribuição das ramificações e a evolução do índice de área foliar em cultivares modernas de soja
}

\author{
Alencar Junior Zanon; Nereu Augusto Streck (*); Gean Leonardo Richter; \\ Camila Coelho Becker; Thiago Schmitz Marques da Rocha; Jossana Ceolin Cera; \\ José Eduardo Minussi Winck; Ânthony Paz Cardoso; Eduardo Lago Tagliapietra; \\ Patric Scolari Weber
}

Universidade Federal de Santa Maria (UFSM), Departamento de Fitotecnia, Avenida Roraima, 1.000, 97105-900 Santa Maria (RS), Brasil. (*) Autor correspondente: nstreck2@yahoo.com.br

Recebido: 24/dez./2014; Aceito: 18/abr./2015

\begin{abstract}
Resumo
Os objetivos neste trabalho foram quantificar a contribuição das ramificações e a evolução do índice de área foliar em cultivares modernas de soja com diferentes grupos de maturação, tipos de crescimento, semeadas em diferentes épocas e regiões produtoras de soja no Rio Grande do Sul. Experimentos de campo foram conduzidos durante o ano agrícola 2013/2014 em Santa Maria, Júlio de Castilhos e em três lavouras comerciais de soja nos municípios de Restinga Sêca, Tupanciretã e Água Santa. Avaliaram-se (data de ocorrência) os estágios reprodutivos e a determinação do índice de área foliar total, máximo, da haste principal e das ramificações em treze cultivares de soja. O índice de área foliar das ramificações contribui com cerca de 31\%, 12,3\% e 11\% do índice de área foliar total nas cultivares determinadas, e com 20,2\%, 11,8\% e 9\% do índice de área foliar total nas cultivares indeterminadas nas semeaduras de setembro, novembro e fevereiro, respectivamente, em Santa Maria. A maioria das cultivares apresentou uma redução no índice de área foliar total, máximo, da haste principal e das ramificações com o atraso da época de semeadura, independentemente do grupo de maturação e tipo de crescimento.
\end{abstract}

Palavras-chave: Glycine max, época de semeadura, tipo de crescimento.

\section{Branches contribution and leaf area index evolution in modern cultivars of soybean}

\begin{abstract}
The purposes of this study were to quantify the branches contribution and the leaf area index evolution in modern cultivars of soybean with different maturity groups, stem termination, sowing in different dates and producing regions of soybean in Rio Grande do Sul. Field experiments were conducted during the growing season 2013/2014 in Santa Maria, Júlio de Castilhos and in three soybean crops on the municipalities of Restinga Sêca, Tupanciretã and Água Santa. It were carried out analysis (occurrence date) of reproductive stages and determination total, maximum, of main stem and of branches of leaf area index in thirteen cultivars of soybean. The leaf area index on the branches contributes with about 31\%, $12.3 \%$ and $11 \%$ of the total leaf area index on the determinate cultivars and with 20.2\%, $11.8 \%$ and $9 \%$ of the total leaf area index on the indeterminate cultivars sowing in September, November and February, respectively, in Santa Maria. Most cultivars showed a reduction on total leaf area index, maximum, of main stem and of branches with the delay on planting date, independently of the maturity group and stem termination.
\end{abstract}

Key words: Glycine max, sowing date, growth type.

\section{INTRODUÇÃO}

A cultura da soja no Brasil tem tido melhoria contínua de genética e tecnologias de manejo. Entre as principais mudanças no sistema produtivo na regiāo Sul do Brasil, destaca-se o aumento da utilizaçáo de cultivares de soja com tipo de crescimento indeterminado e ciclo curto (grupo de maturação entre 4,5 e 7,5) (Richter et al., 2014). Este novo grupo de cultivares começou a ser semeado no Rio Grande do Sul (RS) a partir dos anos 2000 e representou mais de $90 \%$ da área semeada com soja no RS no ano agrícola 2013/2014 (EMATER, 2014), em contraste com as cultivares de tipo determinado e ciclo médio e tardio cultivadas desde os primeiros relatos da soja no RS 
até o final da década de 1990 (Barni \& Matznauer, 2000). A mudança no tipo de crescimento (de determinado para indeterminado) e, principalmente, a redução da duração do ciclo das cultivares modernas promoveram ajustes no manejo realizado na cultura da soja desde a década de 1940 no Sul do Brasil (Tian et al., 2010).

O máximo rendimento da soja é determinado pela capacidade de as plantas interceptarem radiação solar através do índice de área foliar (IAF) e converterem esta radiação em matéria seca pelo processo fotossintético. O IAF é a relação entre a área foliar (AF) e a área de solo ocupada pelo cultivo (Heiffig et al., 2006). A evoluçấo do IAF ao longo do ciclo de desenvolvimento depende da época de semeadura, genótipo, densidade de plantas, espaçamento entre linhas e manejo fitossanitário. A época de semeadura afeta diretamente a disponibilidade dos elementos meteorológicos ao longo do ciclo de desenvolvimento da soja, que por sua vez determinam o período de crescimento vegetativo e a emissáo de ramificaçôes nas cultivares de soja (Setiyono et al., 2011). Por exemplo, o atraso na data de semeadura da cultivar IAS 5 em Augusto Pestana (RS), da metade de novembro para o fim de janeiro, provocou a redução do índice de área foliar máximo de 7,5 para 4,3 (Toledo et al., 2010).

A caracterização do crescimento vegetativo de cultivares de soja em diferentes condiçóes ambientais permite entender as variaçóes na arquitetura de plantas, visando aumentar o rendimento da cultura através de melhoramento genético e manejo, buscando um ideótipo de estrutura de dossel (Setiyono et al., 2011). Existem poucos trabalhos na literatura com objetivo de entender qual a contribuição das ramificações no IAF da soja semeada em diferentes locais e épocas de semeadura (Setiyono et al., 2011). Portanto, estudos regionalizados que descrevam a evolução do crescimento foliar e a contribuição das ramificaçóes ao longo do ciclo e nos principais estágios de desenvolvimento necessitam ser realizados para esse novo grupo de cultivares de soja semeadas no Sul do Brasil. Essa caracterização do IAF em resposta às diferentes disponibilidades climáticas poderá auxiliar a assistência técnica e os produtores a melhorar as práticas de manejo, visando explorar o potencial genético de cada cultivar. Assim, os objetivos neste trabalho foram quantificar a contribuição das ramificações e a evolução do IAF em cultivares modernas de soja com diferentes grupos de maturação, tipos de crescimento, semeadas em diferentes épocas e regiôes produtoras de soja no RS.

\section{MATERIAL E MÉTODO}

Experimentos de campo foram conduzidos durante o ano agrícola 2013/2014 na Universidade Federal de Santa Maria,

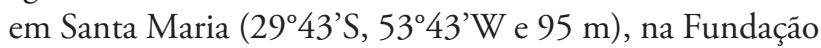
Estadual de Pesquisa Agropecuária - FEPAGRO, em Júlio de Castilhos (29 $9^{\circ} 13^{\prime} \mathrm{S}, 53^{\circ} 40^{\prime} \mathrm{W}$ e $513 \mathrm{~m}$ ), e em três lavouras comerciais de soja nos municípios de Restinga Sêca (29\%49'S, $53^{\circ} 22^{\prime} \mathrm{W}$ e $63 \mathrm{~m}$ ), Tupanciretã (294'S, $53^{\circ} 50^{\prime} \mathrm{W}$ e $456 \mathrm{~m}$ ) e Água Santa $\left(28^{\circ} 10^{\prime} \mathrm{S}, 52^{\circ} 02^{\prime} \mathrm{W}\right.$ e $\left.650 \mathrm{~m}\right)$ no RS (Figura 1). O clima desses locais, segundo a classificação de Köppen, é do tipo Cfa, subtropical úmido com veróes quentes e sem estação seca definida (Kuinchtner \& Buriol, 2001).

Foram utilizadas treze cultivares de soja em cada local, selecionadas por representar diferentes grupos de maturação (GM) e tipo de crescimento determinado (IAS 5 (GM 6.3), FEPAGRO 36 RR (GM 7.1), BRS 246 RR (GM 7.2), Bragg (GM 7.3) e CD 219 RR (GM 8.2)) e indeterminado (NS 4823 RR (GM 4.8), TMG 7161 RR Inox (5.4), TEC 5936 IPRO (5.5), BMX Energia RR (5.5), Igra RA 518 RR (5.7), BMX Turbo (GM 6.0), NA 5909 RG (6.3) e BMX Potência RR (6.7)). Das treze cultivares, duas (Bragg e IAS 5) foram cultivadas nas décadas de 1970, $80 \mathrm{e}$ 90 no RS, e as outras onze cultivares vêm sendo cultivadas no RS desde 2005. Em Santa Maria, foram realizadas três datas de semeadura, antes, durante e após o Zoneamento Agroclimático da Soja. As semeaduras nos outros locais deram-se dentro do período recomendado. A adubação de base, a inoculação e o tratamento das sementes com fungicida e inseticida, e o controle de plantas daninhas, pragas e doenças, foram realizados de acordo com as recomendaçóes técnicas da cultura. Em Santa Maria, os experimentos foram conduzidos com irrigação suplementar, de modo que o crescimento e o desenvolvimento das plantas ocorressem sem deficiência hídrica, e nos demais locais não houve irrigação suplementar, para representar as condiçóes das lavouras de soja em cada um dos locais.

O delineamento experimental nos experimentos conduzidos em Santa Maria foi blocos ao acaso, com quatro repetições. Cada bloco continha 17 linhas, sendo duas linhas de bordadura de cada lado. Cada linha continha uma cultivar e teve $3 \mathrm{~m}$ de comprimento. Em Júlio de Castilhos, o experimento também foi conduzido em blocos ao acaso, com três repetiçóes, sendo cada parcela formada por quatro linhas de cada cultivar com $5 \mathrm{~m}$ de comprimento. Já em Restinga Sêca, Tupanciretã e Água Santa, os experimentos foram conduzidos na forma de parcelas demonstrativas (sem repetição), sendo cada parcela formada por quatro linhas de cada cultivar com $3 \mathrm{~m}$ de comprimento. Em todos os locais, o espaçamento foi de $0,45 \mathrm{~m}$ entre fileiras e a densidade de 30 plantas $\mathrm{m}^{-2}$, usado na maioria das lavouras de soja no Rio Grande do Sul (EMATER, 2014).

A data de emergência foi considerada quando $50 \%$ do total de plantas estavam com os cotilédones acima do solo. Logo após a emissão do primeiro par de folhas unifoliadas, foram marcadas com arame colorido as plantas usadas para avaliaçôes de fenologia e área foliar (Tabela 1). Realizaram-se avaliaçôes (data de ocorrência) dos estágios reprodutivos R1, R5 e R8, segundo a escala de Fehr \& Caviness (1977). As avaliaçôes de área foliar foram feitas medindo-se o comprimento e a largura do folíolo central de todas as 


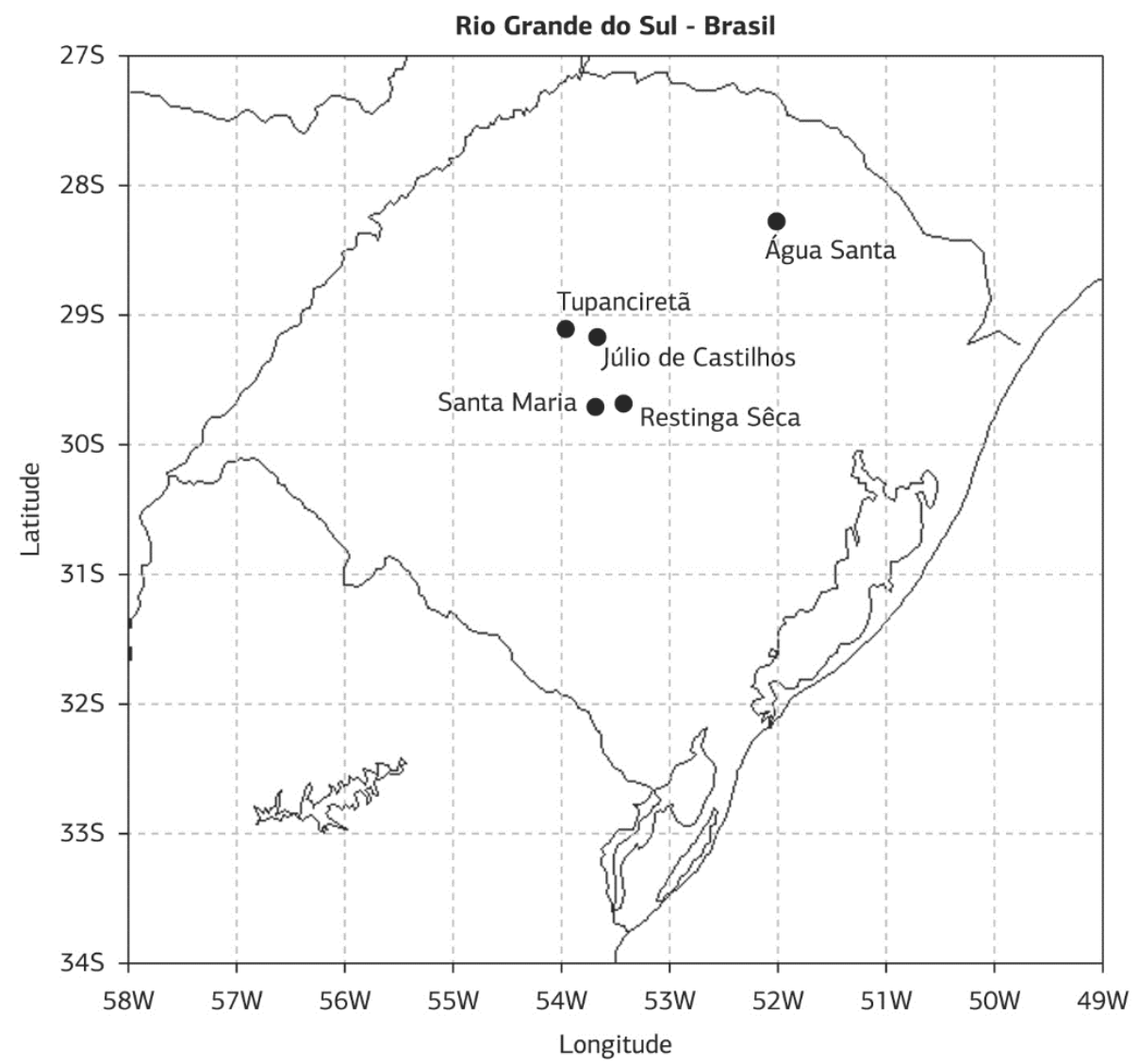

Figura 1. Mapa do Rio Grande do Sul com os locais onde foram conduzidos experimentos com a cultura da soja no ano agrícola 2013/2014, RS, 2014.

Tabela 1. Local de condução, data de semeadura, textura do solo, número de plantas e frequência de avaliação de fenologia e área foliar dos experimentos conduzidos no Rio Grande do Sul no ano agrícola 2013/2014

\begin{tabular}{|c|c|c|c|c|c|c|}
\hline \multirow{2}{*}{ Local } & \multirow{2}{*}{$\begin{array}{l}\text { Data de } \\
\text { semeadura }\end{array}$} & \multirow{2}{*}{ Textura do solo } & \multicolumn{2}{|c|}{ Plantas avaliadas } & \multicolumn{2}{|c|}{ Frequência das avaliações } \\
\hline & & & Fenologia & Área foliar & Fenologia & Área foliar \\
\hline Santa Maria & $27 / 9 / 2013$ & Franco & 20 & 4 & Diária & Quinzenal \\
\hline & $15 / 11 / 2013$ & & 20 & 4 & Diária & Quinzenal \\
\hline & $19 / 2 / 2014$ & & 20 & 4 & Diária & Quinzenal \\
\hline Júlio de Castilhos & $18 / 11 / 2013$ & Argila arenosa & 30 & 3 & 3-4 dias & Estágios R1 e R5 \\
\hline Restinga Sêca & $14 / 11 / 2013$ & Franco & 10 & 3 & 2-3 dias & Estágios R1 e R5 \\
\hline Tupanciretã & $17 / 11 / 2013$ & Argila & 10 & 3 & 10 dias & Estágios R1 e R5 \\
\hline Água Santa & $3 / 12 / 2013$ & Muito argiloso & 10 & 3 & 15 dias & Estágios R1 e R5 \\
\hline
\end{tabular}

folhas da haste principal e das ramificaçóes de cada planta. Em Júlio de Castilhos, Tupanciretâ, Restinga Sêca e Água Santa fizeram-se apenas duas avaliaçóes de área foliar, com o objetivo identificar o IAF próximo ao início do florescimento (R1) e do início do enchimento de grãos (R5). A área foliar foi calculada a partir das equaçôes genético-específicas, estimadas para cada cultivar por Richter et al. (2014). O IAF verde foi calculado somando-se as áreas individuais de folhas e dividindo-se pela área de solo ocupada por uma planta, em mesma unidade de área. Contou-se o número de ramificaçóes com mais de $0,05 \mathrm{~m}$ de 20 plantas de cada cultivar, quando estas encontravam-se no estágio R8. Mais informações sobre o protocolo experimental estão na tabela 1 .

Os dados meteorológicos durante o período experimental foram coletados em duas estaçóes meteorológicas automáticas (EMAs) pertencentes ao $8 .^{\circ}$ Distrito de Meteorologia do Instituto Nacional de Meteorologia (DISME/INMET), localizadas nos municípios de Santa Maria e Passo Fundo, e na estação meteorológica semiautomática pertencente à Fepagro, em Júlio de Castilhos. A EMA de Santa Maria estava localizada a aproximadamente cem metros da área experimental em Santa Maria e a 30 quilômetros da área 
experimental de Restinga Sêca. A EMA de Passo Fundo estava localizada a aproximadamente 35 quilômetros da área experimental de Água Santa, e a EMA de Júlio de Castilhos estava localizada a aproximadamente 300 metros da área experimental na Fepagro e a 30 quilômetros da área experimental de Tupanciretá.

\section{RESULTADOS E DISCUSSÃO}

Nas duas primeiras datas de semeadura em Santa Maria, as plantas foram expostas às condiçóes de temperatura média (Tmed) e fotoperíodo crescente no início do ciclo de desenvolvimento e decrescente no restante do ciclo. Na terceira data de semeadura, a Tmed e o fotoperíodo foram decrescentes durante todo o ciclo. O fotoperíodo a que as plantas de soja foram expostas em Santa Maria variou de 11,1 horas $(21 / 6 / 2014)$ a 14,9 horas $(21 / 12 / 2013)$. Em virtude de as datas de semeaduras terem sido relativamente próximas em Restinga Sêca (14/11/2013), Tupanciretã (17/11/2013), Júlio de Castilhos (18/11/2013) e Água Santa (3/12/2013), as plantas foram expostas a Tmed e fotoperíodo crescente no início do ciclo de desenvolvimento e decrescente no restante do ciclo. Considerando a Tmed durante todo o ciclo da soja nos experimentos semeados nos diferentes locais em novembro e dezembro (época recomendada), verificou-se que as plantas foram expostas a maior Tmed em Santa Maria $\left(24,3^{\circ} \mathrm{C}\right)$ e Júlio de Castilhos $\left(24,1^{\circ} \mathrm{C}\right)$, e menor Tmed em Água Santa $\left(22,5^{\circ} \mathrm{C}\right)$. Os valores de fotoperíodo variaram de 12,4 horas (8/4/2014) até 14,9 horas (21/12/2013) em Júlio de Castilhos e de 12,4 horas (11/4/2013) a 14,8 horas (21/12/2013) em Passo Fundo. Essa variação na disponibilidade dos elementos meteorológicos promoveu uma variaçáo na evolução do índice de área foliar total (IAFtotal), no índice de área foliar máximo (IAFmax) e na contribuição do IAF da haste principal (IAFhp) e das ramificaçôes (IAFram) nas diferentes datas e locais de semeadura nas 13 cultivares de soja.

Nas figuras 2, 3 e 4 (cultivares determinadas) e nas figuras 5, 6 e 7 (cultivares indeterminadas) está representada a evolução do IAFtotal, o IAFhp e o IAFram em três épocas de
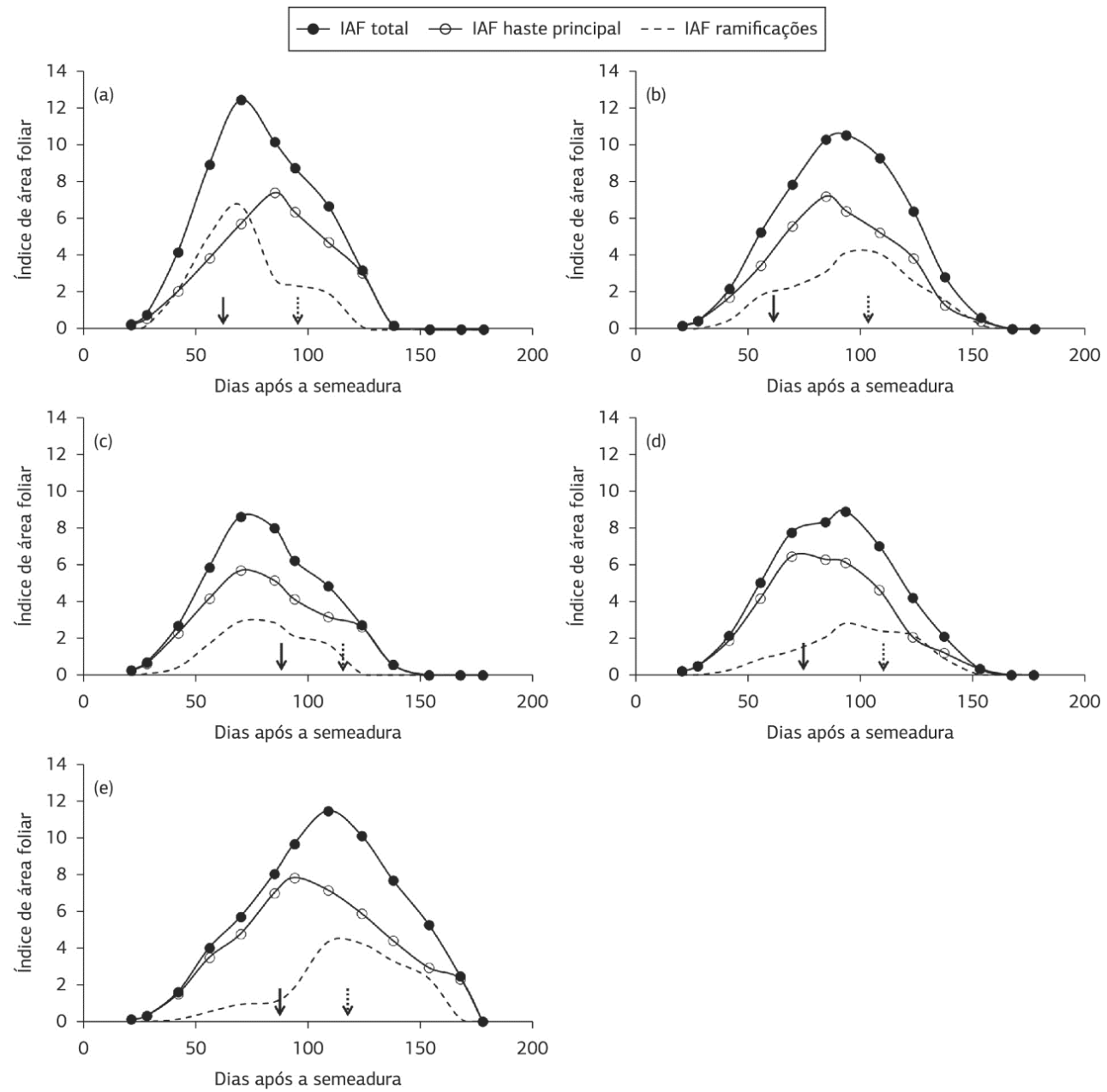

Figura 2. Evolução do índice de área foliar total (IAFtotal), na haste principal (IAF haste principal) e nas ramificaçôes (IAF ramificações) das cultivares de soja de tipo de crescimento determinado (a) IAS 5, (b) Fepagro 36 RR, (c) Bragg, (d) BRS 246 RR e (e) CD 219 semeadas em 27/9/2013. A seta contínua indica o estágio R1 e a seta tracejada indica o estágio R5. Santa Maria, 2013-2014. 

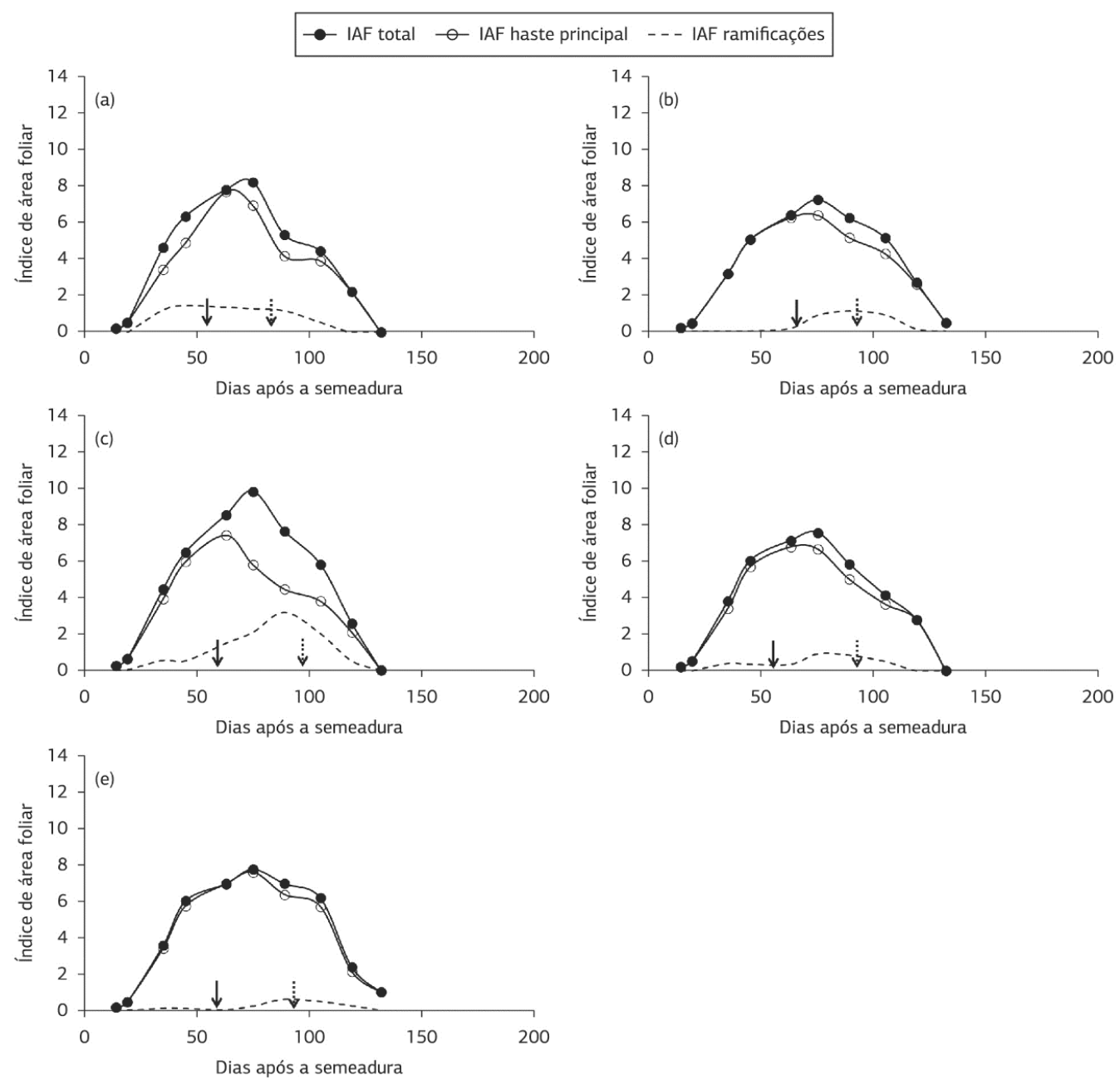

Figura 3. Evolução do índice de área foliar total (IAFtotal), na haste principal (IAF haste principal) e nas ramificaçōes (IAF ramificaçôes) das cultivares de soja de tipo de crescimento determinado (a) IAS 5, (b) Fepagro 36 RR, (c) Bragg, (d) BRS 246 RR e (e) CD 219 semeadas em 15/11/2013. A seta contínua indica o estágio R1 e a seta tracejada indica o estágio R5. Santa Maria, 2013-2014.

semeadura (27/9/2013, 15/11/2013 e 6/2/2014) em Santa Maria. A maioria das cultivares apresentou uma redução no IAFmax com o atraso da época de semeadura, independentemente do grupo de maturação e tipo de crescimento. O IAFmax médio das 13 cultivares na época 1 foi de 8,9, na época 2 de 7,2 e na época 3 de 3,0. Essa redução do IAFmax ocorreu em virtude do encurtamento do ciclo de desenvolvimento com o atraso da semeadura, que pode ser explicado pelo fato de a soja ser uma planta de dia curto (Sinclair et al., 2005), ou seja, com o atraso da semeadura ocorreu a diminuição do comprimento do dia, e as cultivares foram induzidas mais cedo a florescerem, o que provocou a aceleração do ciclo de desenvolvimento (Setiyono et al., 2007). As únicas exceçóes foram as cultivares TEC5936 IPRO e Bragg, que aumentaram o IAFmax da primeira para segunda época de semeadura de 8,2 para 8,4 e 8,6 para 9,8 , respectivamente. Os menores IAFmax nessas cultivares na primeira época de semeadura podem ser explicados pela maior sensibilidade ao fotoperíodo. Apesar de a TEC5936 IPRO ser uma cultivar moderna, possivelmente o fotoperíodo a que as plantas foram expostas durante o período crítico de indução floral (V0-R0) (Setiyono et al., 2007) promoveu a antecipação do início do florescimento na época 1 (Figura 5h), quando comparado com a época 2 (Figura $6 \mathrm{~h}$ ), que por sua vez reduziu o crescimento vegetativo na semeadura de setembro. Já na cultivar Bragg, a ausência do gene da juvenilidade (maior sensibilidade ao fotoperíodo) provocou a antecipação do florescimento na semeadura de setembro, e por ser uma cultivar de tipo de crescimento determinado, teve seu crescimento vegetativo cessado rapidamente após o R1 (Bonato et al., 1998).

O IAFmax médio das oito cultivares indeterminadas e das cinco cultivares determinadas foi de 8,9 e 10,4 na época 1, de 6,7 e 8,0 na época 2 , e de 2,6 e 3,7 na época 3, respectivamente. A hipótese que explica o maior IAFmax médio nas cultivares de tipo determinado deve-se ao fato de essas pertencerem a grupos de maturaçáo maiores, quando comparado às cultivares indeterminadas. Como a maioria das cultivares atualmente semeadas no Sul do Brasil apresentam grupos de maturação 

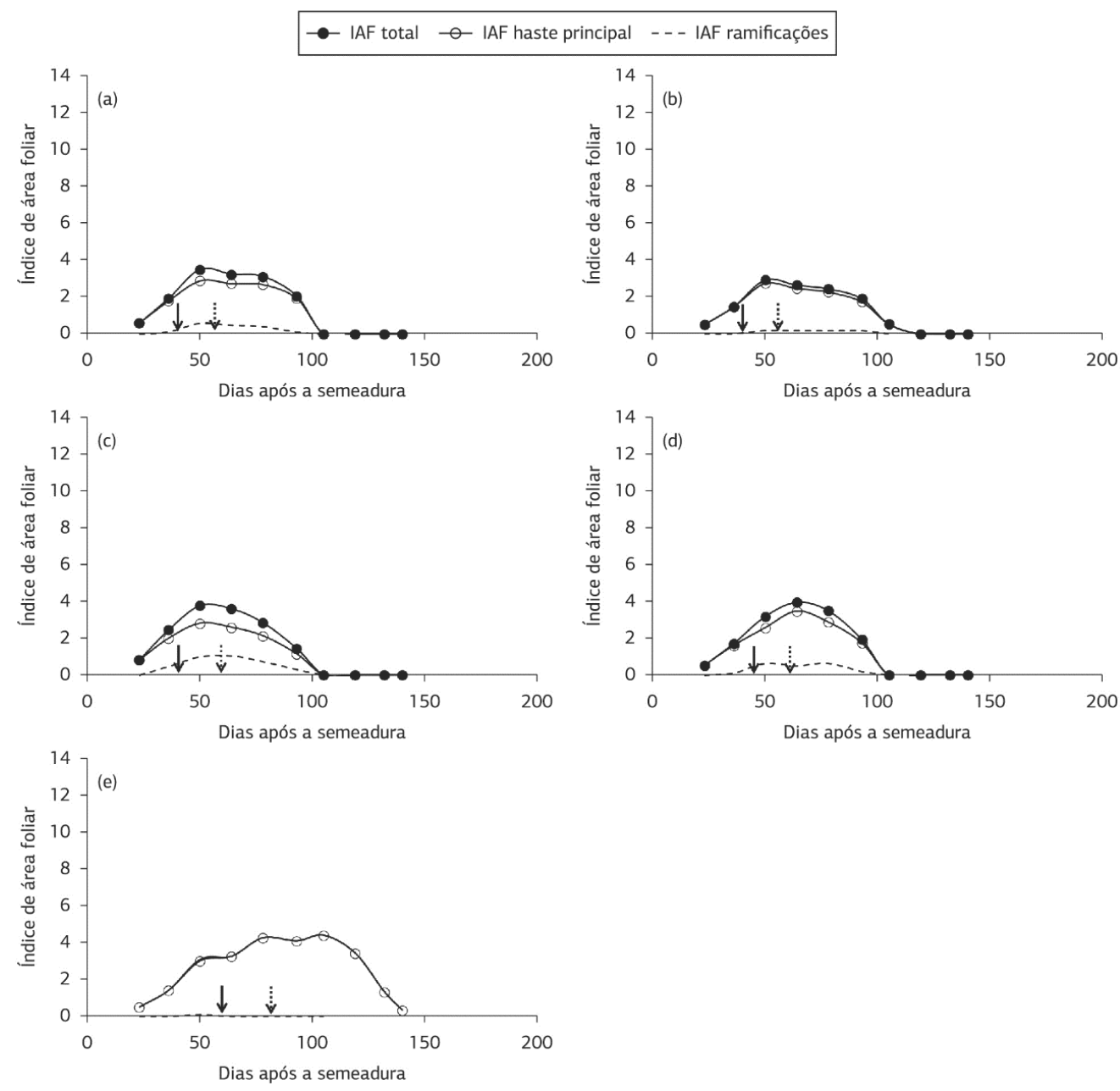

Figura 4. Evolução do índice de área foliar total (IAFtotal), na haste principal (IAF haste principal) e nas ramificações (IAF ramificações) das cultivares de soja de tipo de crescimento determinado (a) IAS 5, (b) Fepagro 36 RR, (c) Bragg, (d) BRS 246 RR e (e) CD 219 semeadas em 19/2/2013. A seta contínua indica o estágio R1 e a seta tracejada indica o estágio R5. Santa Maria, 2013-2014.

baixo (Richter et al., 2014), e consequentemente menor IAFmax quando comparado às cultivares antigas (grupos de maturação alto), os assistentes técnicos e os produtores de soja devem ter maior atençáo no manejo de insetos desfolhadores. As cultivares determinadas e indeterminadas que apresentaram os maiores e menores valores de IAFmax na semeadura de setembro foram a IAS $5(12,5)$, Bragg $(8,6)$ e BMX Potência RR (12,6), NS 4823 RR $(4,6)$, respectivamente. $\mathrm{Na}$ época recomendada (novembro), os valores de IAFmax variaram de 9,8 (Bragg) a 7,2 (Fepagro $36 \mathrm{RR}$ ) nas determinadas e de 8,4 (TEC 5936 IPRO) a 5,6 (NA 5909 RR) nas indeterminadas. Já na semeadura de fevereiro, os valores de IAFmax foram menores, variando de 4,4 (CD $219 \mathrm{RR}$ ) até 2,9 (Fepagro $36 \mathrm{RR}$ ) nas determinadas e de 3,0 (BMX Potência RR) até 2,0 (NS 4823 RR) nas indeterminadas. Os valores de IAFmax encontrados para a cultivar IAS 5 na semeadura de 15/11/2013 (8,2) e 6/2/2014 $(3,5)$ estão próximos aos valores encontrados com a mesma cultivar semeada em 19/11/2004 (7,6) e 31/1/2006 (4,1) no município de Augusto Pestana/RS (Toledo et al., 2010).

$\mathrm{Na}$ primeira $(27 / 9 / 2013)$ e segunda $(15 / 11 / 2013)$ época de semeadura, as cultivares de tipo determinado e indeterminado apresentaram evoluçóes de IAF distintas ao longo das estaçóes de crescimento. Na semeadura do final de setembro, as cultivares determinadas tiveram a maior taxa de crescimento dos 25 dias após a semeadura até por volta do estágio R1 (Figura 2). Já as cultivares indeterminadas apresentaram uma taxa de crescimento mais lenta, cessando somente próximo ao início do enchimento de grãos (estágio R5) na maioria das cultivares (Figura 5). Na semeadura na época recomendada (novembro), as 13 cultivares iniciaram mais rapidamente o desenvolvimento foliar (em torno de dez dias após a semeadura), e o IAFmax foi atingido na maioria das cultivares determinadas logo após o R1 (Figura 3) e nas indeterminadas próximo ao estágio R5, exceto a BMX Potência (Figura 6). Resultados similares foram encontrados por Toledo et al. (2010), que estudando 
uma cultivar determinada (IAS 5), em semeadura nos meses de novembro e dezembro no RS, também verificaram que a velocidade máxima de aumento do IAF ocorre entre os estágios V6 e R1. Já na semeadura de 6/2/2014, a máxima taxa de crescimento ocorreu dos 20 dias após a semeadura até próximo ao estágio R5 nas 13 cultivares (Figuras 4 e 7).
Independentemente do tipo de crescimento e da época de semeadura, a contribuição da área foliar das ramificações para o IAFtotal iniciou quando as plantas tinham em torno de 4 a 6 folhas na haste principal, o que concorda com Thomas \& Mundstock (2005), que determinaram que as ramificaçôes começam a ser emitidas na planta quando esta encontra-se entre
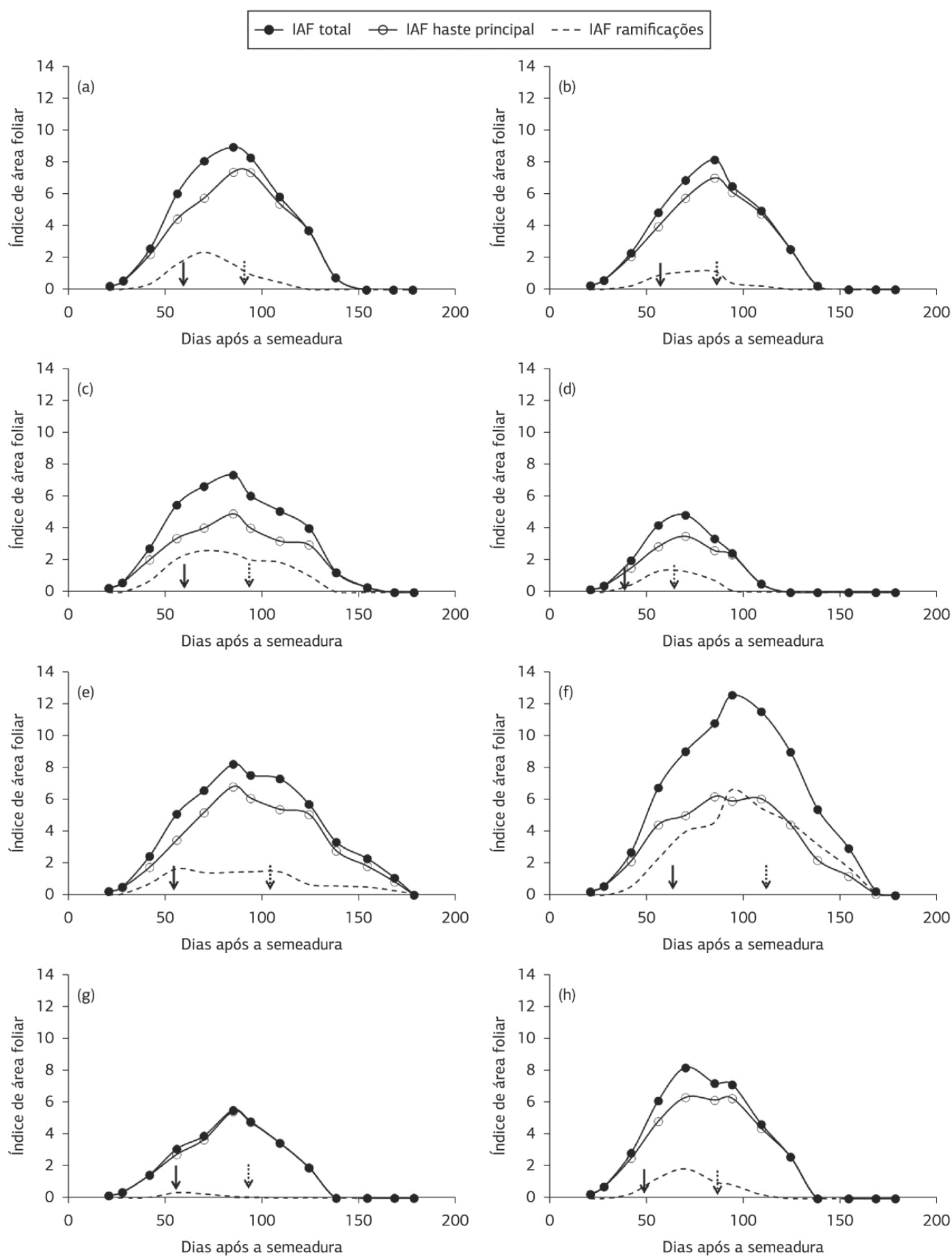

Figura 5. Evolução do índice de área foliar total (IAFtotal), na haste principal (IAF haste principal) e nas ramificaçóes (IAF ramificaçôes) das cultivares de soja de tipo de crescimento indeterminado (a) BMX Turbo RR, (b) BMX Energia RR, (c) NA 5909 RR, (d) NS 4823 RR, (e) Igra 518 RR, (f) BMX Potência RR, (g) TMG 7161 RR Inox e (h) TEC 5936 IPRO semeadas em 27/9/2013. A seta contínua indica o estágio R1 e a seta tracejada indica o estágio R5. Santa Maria, 2013-2014. 
os estágios $\mathrm{V} 3$ e V5. O IAFhp e o IAFram foram responsáveis por $84,1 \%$ e $15,9 \%$ do IAFtotal na média das 13 cultivares e três semeaduras em Santa Maria (Tabela 2). De maneira geral, verificou-se que o número (Figura 8) e a contribuição das ramificaçôes no IAF foram diminuindo com o atraso da época de semeadura. Na semeadura em setembro, o IAFram contribuiu com $31 \%$ e $20,2 \%$ nas cultivares determinadas e indeterminadas, respectivamente. Essa contribuição diminuiu para $12,3 \%$ na semeadura em novembro e $11 \%$ na de fevereiro nas cultivares determinadas, e nas cultivares indeterminadas o decréscimo foi de $11,8 \%$ em novembro para 9,0\% em fevereiro. A menor contribuição do IAFram
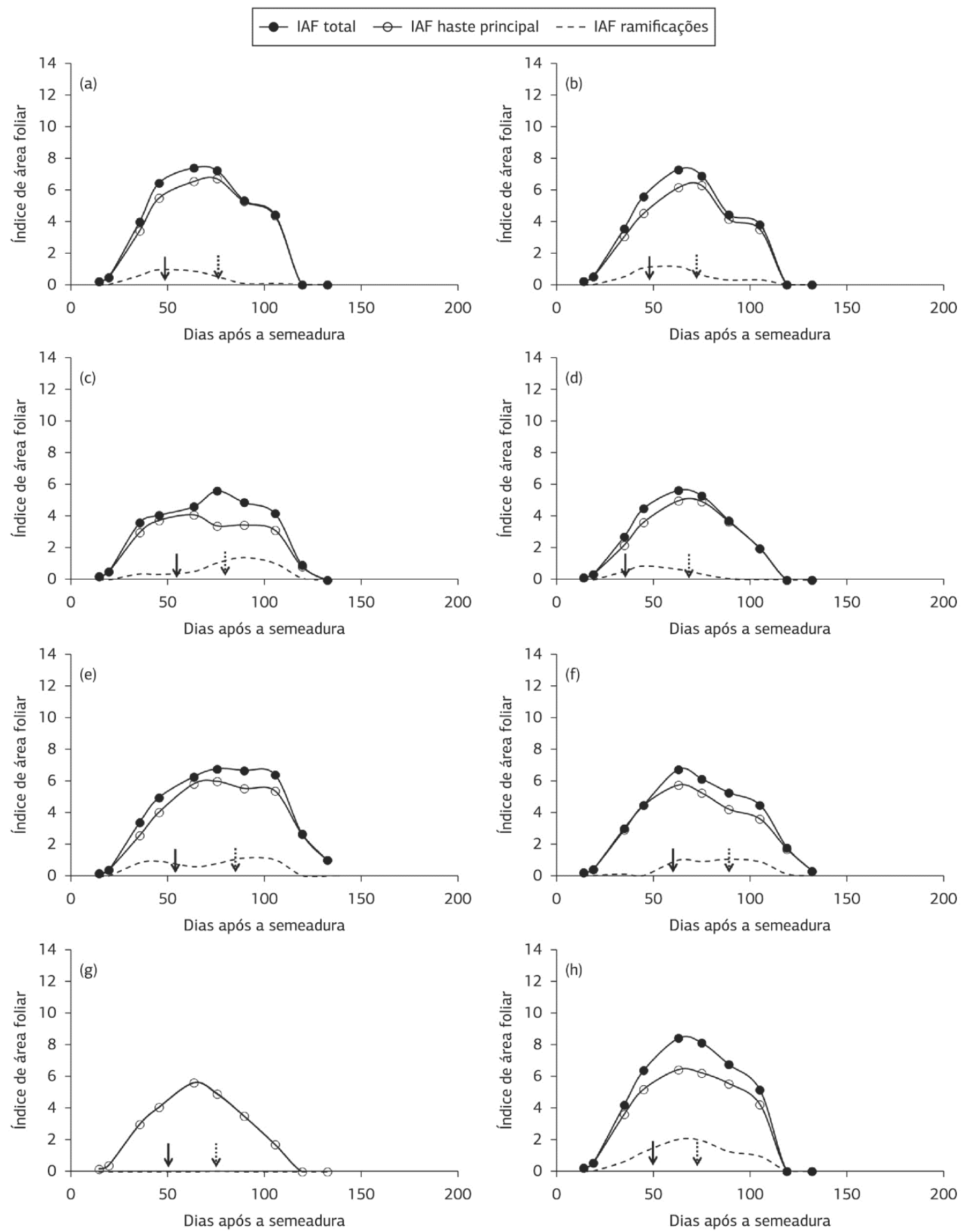

Figura 6. Evolução do índice de área foliar total (IAFtotal), na haste principal (IAF haste principal) e nas ramificaçôes (IAF ramificaçôes) das cultivares de soja de tipo de crescimento indeterminado (a) BMX Turbo RR, (b) BMX Energia RR, (c) NA 5909 RR, (d) NS 4823 RR, (e) Igra 518 RR, (f) BMX Potência RR, (g) TMG 7161 RR Inox e (h) TEC 5936 IPRO semeadas em 15/11/2013. A seta contínua indica o estágio R1 e a seta tracejada indica o estágio R5. Santa Maria, 2013-2014. 
está associada ao encurtamento do ciclo de desenvolvimento e à diminuição do número de ramificaçôes com o atraso da semeadura. Destaca-se que a contribuição do IAFram foi muito pequena no IAFtotal da cultivar TMG 7161 RR Inox (Figuras 5g, 6h e 7g), o que pode ser atribuída a uma característica genética desta cultivar. Logo, a caracterização da capacidade de ramificar, e consequentemente da contribuição do IAFram no IAFtotal de cada genótipo, é importante para definição de cruzamentos em programas de melhoramento, nas recomendaçốes de manejo (Setiyono et al., 2011),
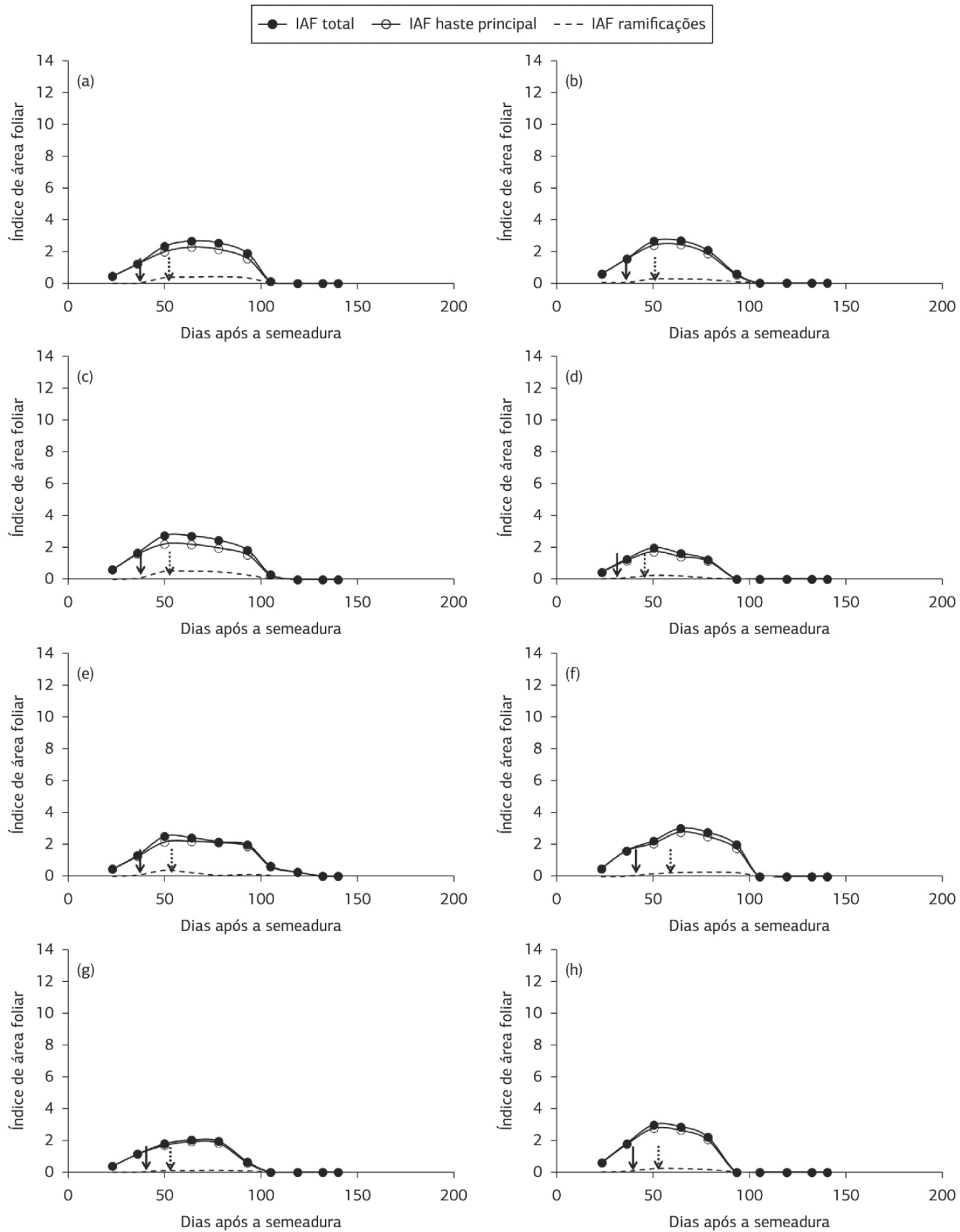

Figura 7. Evolução do índice de área foliar total (IAFtotal), na haste principal (IAF haste principal) e nas ramificaçóes (IAF ramificaçôes) das cultivares de soja de tipo de crescimento indeterminado (a) BMX Turbo RR, (b) BMX Energia RR, (c) NA 5909 RR, (d) NS 4823 RR, (e) Igra 518 RR, (f) BMX Potência RR, (g) TMG 7161 RR Inox e (h) TEC 5936 IPRO semeadas em 19/2/2013. A seta contínua indica o estágio R1 e a seta tracejada indica o estágio R5. Santa Maria, 2013-2014. 
Tabela 2. Porcentagem do índice de área foliar total que está na haste principal e nas ramificaçóes nas 13 cultivares de soja, nas três datas de semeadura em Santa Maria, RS, no ano agrícola 2013/2014

\begin{tabular}{|c|c|c|c|c|c|c|}
\hline \multirow{2}{*}{ Cultivar } & \multicolumn{2}{|c|}{$27 / 9 / 2013$} & \multicolumn{2}{|c|}{$15 / 11 / 2013$} & \multicolumn{2}{|c|}{$19 / 2 / 2014$} \\
\hline & HP & RAM & HP & RAM & HP & RAM \\
\hline NS 4823 RR & 77,9 & 22,1 & 89,8 & 10,3 & 90,6 & 9,4 \\
\hline BMX Energia RR & 89,5 & 10,5 & 88,2 & 11,8 & 92,0 & 8,0 \\
\hline Igra RA 518 RR & 81,4 & 18,6 & 86,3 & 13,7 & 92,3 & 7,7 \\
\hline BMX Turbo RR & 84,0 & 16,0 & 91,5 & 8,5 & 87,4 & 12,6 \\
\hline NA 5909 RG & 68,8 & 31,2 & 82,1 & 17,9 & 84,0 & 16,0 \\
\hline TMG 7161 RR Inox & 97,1 & 2,9 & 100,0 & 0,0 & 95,0 & 5,0 \\
\hline TEC 5936IPRO & 85,9 & 14,1 & 80,1 & 20,0 & 94,3 & 5,7 \\
\hline BMX Potência RR & 53,9 & 46,1 & 87,9 & 12,1 & 92,6 & 7,4 \\
\hline Média Indeterminada & 79,8 & 20,2 & 88,2 & 11,8 & 91,0 & 9,0 \\
\hline IAS 5 & 62,8 & 37,2 & 82,9 & 17,1 & 88,2 & 11,8 \\
\hline Fepagro 36 RR & 64,0 & 36,0 & 91,8 & 8,2 & 94,4 & 5,6 \\
\hline BRS 246 RR & 76,1 & 23,9 & 91,3 & 8,7 & 86,4 & 13,6 \\
\hline Bragg & 70,8 & 29,2 & 77,0 & 23,0 & 76,5 & 23,5 \\
\hline CD 219 RR & 71,4 & 28,6 & 95,6 & 4,4 & 99,6 & 0,4 \\
\hline Média Determinada & 69,0 & 31,0 & 87,7 & 12,3 & 89,0 & 11,0 \\
\hline Média total & 74,4 & 25,6 & 88,0 & 12,0 & 90,0 & 10,0 \\
\hline
\end{tabular}

HP: Área foliar da haste principal. RAM: Área foliar das ramificaçóes.

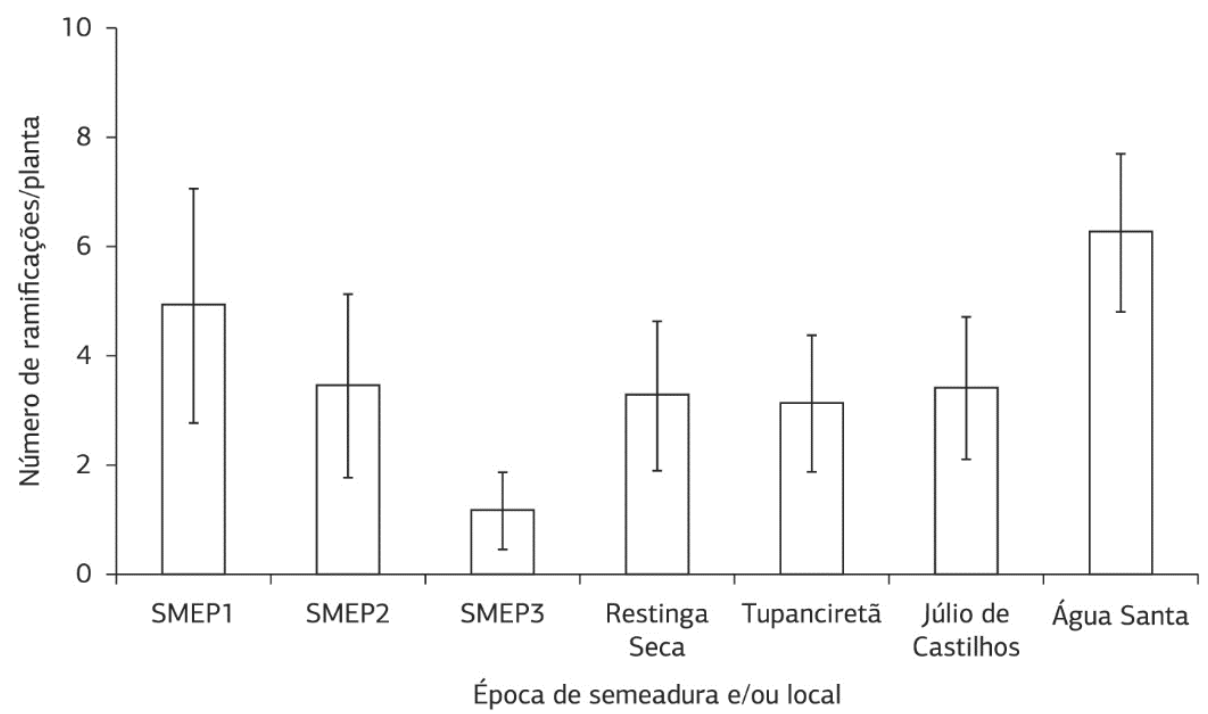

Figura 8. Número de ramificaçóes médio de treze cultivares de soja (BMX Turbo RR, BMX Energia RR, NA 5909 RR, NS 4823 RR, Igra 518 RR, BMX Potência RR, TMG 7161 RR Inox, TEC 5936 IPRO, IAS 5, Fepagro 36 RR, Bragg, BRS 246 RR e CD 219 RR) semeadas em 27/9/2013 (SMEP1), 15/11/2013 (SMEP2) e 6/2/2014 (SMEP3) em Santa Maria, 14/11/2013 em Restinga Sêca, 17/11/2013 em Tupanciretá, 18/11/2013 em Júlio de Castilhos e 3/12/2013 em Água Santa no ano agrícola 2013/2014, RS.

como densidade de semeadura, pois aquelas cultivares que têm menor capacidade de emitir ramificações podem ser semeadas em uma densidade mais elevada.

$\mathrm{Na}$ figura 9 estão representados o IAFtotal, o IAFhp e o IAFram próximos aos estágios R1 e R5 de treze cultivares de soja semeadas em Júlio de Castilhos, e em três lavouras comerciais nos municípios de Restinga Sêca, Tupanciretã e Água Santa. Comparando os valores de IAFmax das 13 cultivares do experimento semeado em novembro em Santa Maria com irrigação (Figuras 3 e 6) com os experimentos conduzidos nos outros locais sem irrigação e com datas próximas de semeadura, observa-se que para as cultivares semeadas em Santa Maria apresentaram os maiores valores de IAFmax, exceto as cultivares NS 4823RR semeadas em Tupanciretã (Figura 9d), BRS 246 RR semeada em Restinga Sêca (Figura 9c), CD 219 RR semeada em Júlio de Castilhos (Figura 9b) e a cultivar TMG 7161 RR Inox semeada em Júlio de Castilhos e Restinga Sêca (Figura 9b e 9c). A explicação para o maior IAFmax ter ocorrido no experimento em Santa Maria é a provável deficiência hídrica nos experimentos em Júlio de Castilhos e nas lavouras comerciais em Restinga Sêca, Tupanciretá e Água Santa ao longo do ciclo de desenvolvimento 

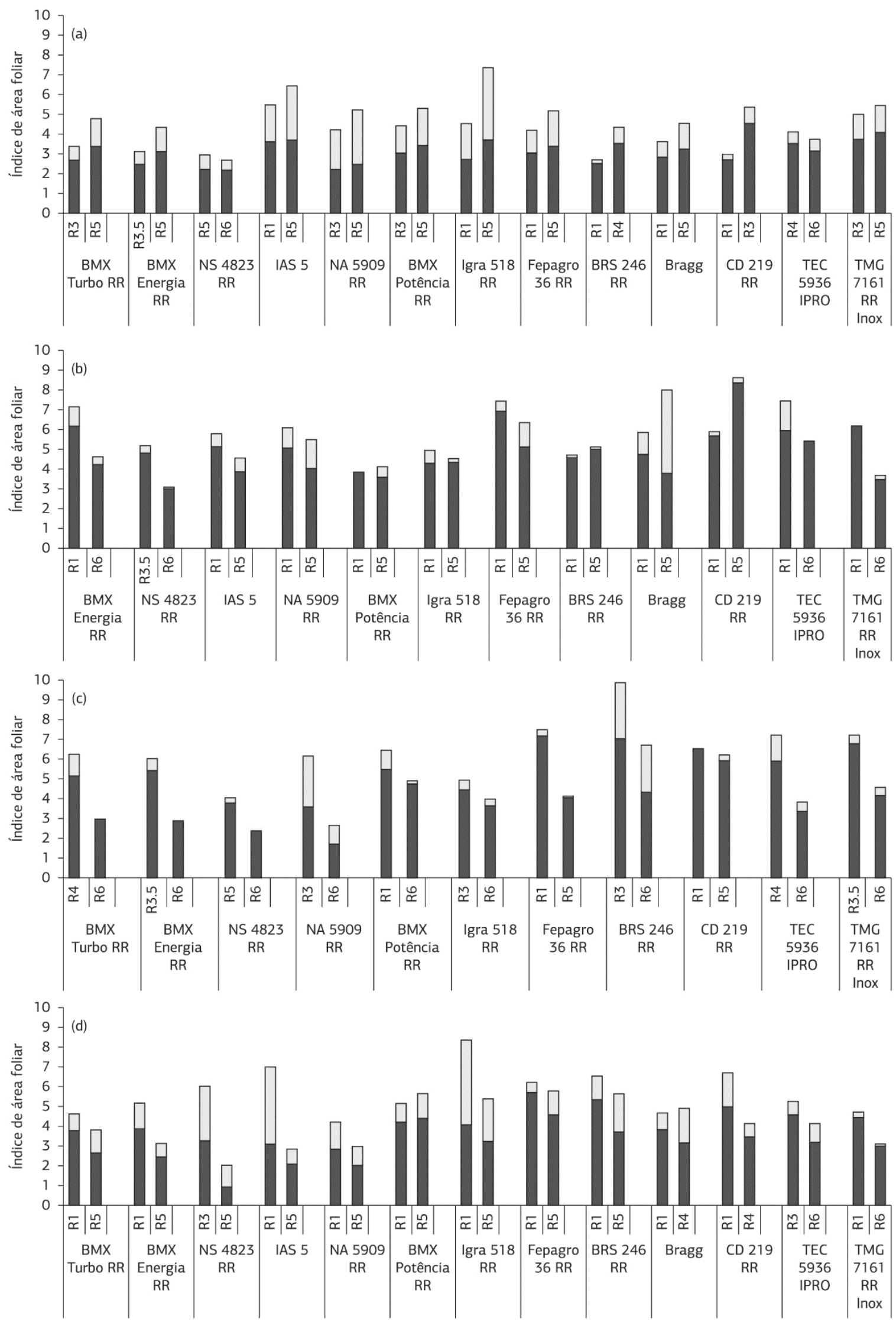

Figura 9. Índice de área foliar na haste principal (barra sólida) e nas ramificaçôes (barra vazada) de treze cultivares de soja semeadas em Água Santa (a), Júlio de Castilhos (b), Restinga Sêca (c) e Tupanciretá (d), RS, 2013-2014. * No experimento em Júlio de Castilhos e Restinga Sêca não foram realizadas avaliações nas cultivares BMX Turbo RR 
da cultura, mas principalmente na fase vegetativa da soja. Em Júlio de Castilhos e Tupanciretâ, choveu apenas $6 \mathrm{~mm}$ no período de 27/1/2014 até 18/2/2014. Já em Restinga Sêca, choveu $28 \mathrm{~mm}$ de 14/12/2013 até 7/1/2014, e em Água Santa registraram-se apenas $16 \mathrm{~mm}$ entre 10/12/2013 e 1/1/2014. A perda de turgor celular é o primeiro efeito do estresse hídrico, provocando assim uma redução da área foliar devido à restrição do crescimento das folhas durante a deficiência hídrica (Taiz \& Zeiger, 2006). Além disso, nos experimentos em Júlio de Castilhos, Restinga Sêca e Tupanciretã, o maior IAFmax foi registrado próximo do estágio R1 na maioria das cultivares, e após verificou-se uma queda no valor de IAFmax até o estágio R5, exceto nas cultivares BMX Potência RR, BRS 246 RR, Bragg e CD 219 RR em Júlio de Castilhos, e a cultivar Bragg em Tupanciretá. Essa reduçáo no IAFmax, principalmente nas cultivares indeterminadas, comparada com o que ocorreu no experimento com irrigação (Santa Maria), também pode ser atribuída à deficiência hídrica durante o desenvolvimento da soja. Pois, além da perda de turgor das células, o estresse por falta de água faz com que as raízes enviem sinais químicos promovendo o aumento da concentração de ácido abscísico nas folhas (Taiz \& Zeiger, 2006), que causa a queda precoce destas, diminuindo assim o IAFtotal.

$\mathrm{O}$ menor IAF das cultivares atualmente semeadas (indeterminada e grupos de maturação baixo), quando comparado às cultivares tradicionalmente semeadas no Sul do Brasil até os anos 2000 (tipo determinado e grupo de maturação maior que 6.5), em condiçôes sem deficiência hídrica, obtidas neste trabalho, comprovam a evolução genética da cultura da soja. Pois, mesmo com menor IAF, a produtividade média da soja no Sul do Brasil atualmente é maior (3041 kg ha-1) do que antes dos anos 2000 (2085 $\mathrm{kg} \mathrm{ha}^{-1}$ ) (EMATER, 2014), ou seja, as cultivares modernas são mais eficientes.

\section{CONCLUSÃO}

O IAFram contribui com cerca de $31 \%, 12,3 \%$ e $11 \%$ do IAFtotal nas cultivares determinadas e com $20,2 \%, 11,8 \%$ e $9 \%$ do IAFtotal nas cultivares indeterminadas nas semeaduras de setembro, novembro e fevereiro, respectivamente, em Santa Maria.

Há reduçáo dos valores de IAFmax, IAFhp e IAFram com o atraso da época de semeadura, independentemente do grupo de maturação e tipo de crescimento.

Nas semeaduras de setembro e novembro, as cultivares de tipo determinado apresentam o IAFmax próximo de $\mathrm{R} 1$, enquanto as cultivares indeterminadas apresentam o IAFmax próximo de R5. Já na semeadura de fevereiro, todas as cultivares apresentam o IAFmax próximo de R5.

\section{REFERÊNCIAS}

Barni, N. A., \& Matznauer, R. (2000). Ampliação do calendário de semeadura da soja no Rio Grande do Sul pelo uso de cultivares adaptados aos distintos ambientes. Pesquisa Agropecuária Gaúcha, 6, 189-203.

Bonato, E. R., Bertagnolli, P. F., Ignaczak, J. C., Tragnago, J. L., \& Rubin, S. A. L. (1998). Desempenho de cultivares de soja em três épocas de semeadura, no Rio Grande do Sul. Pesquisa Agropecuária Brasileira, 33, 879-884.

Empresa de Assistência Técnica e Extensão Rural - EMATER (2014). Levantamento de área semeada com soja no Rio Grande do Sul. Porto Alegre: Emater. Recuperado em 20 de dezembro de 2014, de http:// www.emater.tche.br/site/servicos/informacoes-agropecuarias.php\#. VYrxQpB0zIU.

Fehr, W. R., \& Caviness, C. E. (1977). Stages of soybean development (Special Report, 80). Ames: Iowa State University of Science and Technology. $15 \mathrm{p}$.

Heiffig, L. S., Câmara, G. M. S., Marques, L. A., Pedroso, D. B., \& Piedade, S. M. S. (2006). Fechamento e índice de area foliar da cultura da soja em diferentes arranjos espaciais. Bragantia, 65, 285-295. http:// dx.doi.org/10.1590/S0006-87052006000200010.

Kuinchtner, A., \& Buriol, G. A. (2001). Clima do Estado do Rio Grande do Sul segundo a classificação climática de Köppen e Thornthwaite. Disciplinarum Scientia, 2, 171-182.

Richter, G. L., Zanon, A. J., Streck, N. A., Guedes, J. V. C., Kräulich, B., Rocha, T. S. M., Winck, J. E. M., \& Cera, J. C. (2014). Estimativa da área de folhas de cultivares antigas e modernas de soja por método não destrutivo. Bragantia, 73, 416-425. http://dx.doi.org/10.1590/16784499.0179

Setiyono, T. D., Bastidas, A. M., Cassman, K. G., Weiss, A., Dobermann, A., \& Specht, J. E. (2011). Nodal leaf area distribution in soybean plants grown in high yield environments. Agronomy Journal, 103, 1198-1205. http://dx.doi.org/10.2134/agronj2011.0051.

Setiyono, T. D., Weiss, A., Specht, J. E., Bastidas, A. M., Cassman, K. G., \& Dobermann, A. (2007). Understanding and modeling the effect of temperature and daylenght on soybean phenology under highyield conditions. Field Crops Research, 100, 257-271. http://dx.doi. org/10.1016/j.fcr.2006.07.011.

Sinclair, T. R., Neumaier, N., Farias, J. R. B., \& Nepomuceno, A. L. (2005). Comparison of vegetative development in soybean cultivars for low latitude environments. Field Crops Research, 92, 53-59. http:// dx.doi.org/10.1016/j.fcr.2004.08.008.

Taiz, L., \& Zeiger, E. (2006). Plant physiology (4th ed.). Sunderland: Sinauer Associates. 764 p.

Thomas, A. L., \& Mundstock, C. M. (2005). Soja: fatores que afetam o crescimento e o rendimento de grãos. Porto Alegre: Universidade Federal do Rio Grande do Sul, Evangraf. 31 p.

Tian, Z., Wang, X., Lee, R., Li, Y., Specht, J. E., Nelson, R. L., McClean, P. E., Qiu, L., \& Ma, J. (2010). Artificial selection for determinate growth habit in soybean. Proceedings of the National Academy of Sciences of the United States of America, 107, 8563-8568. http:// dx.doi.org/10.1073/pnas.1000088107. PMid:20421496.

Toledo, N. T., Muller, A. G., Berto, J. L., \& Mallmann, C. E. S. (2010). Ajuste do modelo fototérmico de estimativa do desenvolvimento e do índice de área foliar de soja. Revista Brasileira de Engenharia Agrícola e Ambiental, 14, 288-295. 